\title{
A RELAÇÃO UNIVERSIDADE E SOCIEDADE: A "PROBLEMATIZAÇÃO" NOS PROJETOS ARTICULADOS DE ENSINO, PESQUISA E EXTENSÃO
}

\section{Silvio Sánchez Gamboa Márcia Chaves}

\section{RESUMO}

É objetivo deste relato de experiência apresentar os resultados de um processo coletivo de elaboração de conhecimentos suscitados no cotidiano escolar de aulas de Estudos do Lazer e Recreação Comunitária tendo como campo de atuação as áreas de extensão da Universidade Federal de Alagoas, utilizando os protocolos da pesquisa científica que tem como base a problematização tanto da realidade onde se inserem as práticas de extensão como as práticas pedagógicas e sociais. Este relato foi organizado em três partes: a) breve descrição das experiências geradoras, que motivaram a busca de uma maior sustentação científica e a necessidade de um referencial teórico metodológico que fundamente as práticas pedagógicas e de extensão; b) enunciação dos núcleos de referências que servem de premissas para a compreensão da prática; e, c) exposição dos principais resultados do processo coletivo estabelecido em torno da Linha de Estudos e Pesquisas em Educação Física \& Esporte e Lazer (LEPEL) e finalmente, a maneira de conclusões, destacamos a importância da problematização e dos métodos científicos no aprimoramento das ações pedagógicas e transformadoras do ensino e a extensão.

\section{PALAVRAS-CHAVE}

Universidade; Sociedade; Ensino; Pesquisa; Extensão

\section{THE RELATION UNIVERSITY AND SOCIETY: THE "PROBLEMS DISCUSSION" IN THE ARTICULATED PROJECTS OF EDUCATION, SEARCHES AND EXTENSION}

\begin{abstract}
The objective of this relate of experience is to present the results of a collective process for elaboration of knowledge aroused in the school daily in "Studies of the Leisure" and "Communitarian Recreation" classes, having as acting field the extension areas of the Alagoas Federal University, using the protocols of the scientific research, being based in the problems discussion, as reality where the extension practices are insert, as of the pedagogical and social practices. This relate was organized in three parts: a) brief description of generative experiences, that had motivated the group to look for more scientific sustentation and references of theory and method of the pedagogical and extension practices; b) enunciation of cores of references that are premises for the understanding of the practical; and, $c$ ) exposition of the main results of the collective process established around the Studies and Research in Physical Education, Sport and Leisure Group. Finally, to conclude, we detach the importance of the problems discussion and the scientific methods in the upgrading of the pedagogical and transformer actions of education and the extension.
\end{abstract}

\section{KEYWORDS}

University; Society; Education; Research; Extension. 


\section{RELATO DE EXPERIÊNCIA Área Temática: Filosofia da Educação}

\section{INTRODUÇÃO}

O debate sobre as funções básicas da universidade brasileira ganha um novo patamar com o Decreto Nº 2.306 de 1997, Art. $8^{\circ}$ que alterou o paradigma de ensino superior antes centrado na universidade pública dedicada ao ensino, a pesquisa e a extensão. A nova legislação facilita as atividades de ensino dissociadas da pesquisa e a extensão abrindo espaço jurídico para que outras instituições, faculdades e centros universitários, na sua maioria privados, se tornem o modelo predominante com $75 \%$ da matrícula. Tal política pretende superar o pesado déficit acumulado do baixo índice de escolaridade superior, inferior aos países industrializados e ainda mais gritantes no quadro dos países da América Latina, onde o Brasil ocupa o penúltimo lugar superando apenas a Nicarágua. Essa forma facilitada e empobrecida de formação profissional inclui outras medidas nefastas como o PRONEX (Programa de Apoio a Núcleos de Excelência), a GED e GID (Gratificações de estímulo ou Incentivo a docência), o PNG (Programa Nacional da Graduação e as Diretrizes para o Ensino) e a Lei de Inovação Tecnológica, estabelecida para desmontar o princípio da indissociabilidade entre ensino pesquisa, ensino e extensão. Entretanto apesar desse quadro nefasto tem outra universidade que reage contra a destruição insistindo no princípio da indissociabilidade entre ensino-pesquisa-extensão e na formação de intelectuais orgânicos. É a universidade que constrói sua identidade gerando um conhecimento exaustivo da problemática da sociedade onde atua, recuperando e conservando saberes e conhecimentos sobre múltiplos as problemáticas significativas dessa sociedade. Essa outra universidade hoje se organiza em grupos de pesquisa dedicados a sistematizarem informações e gerarem massa crítica sobre a problemática da sociedade onde atuam. Os eixos aglutinadores dos grupos de pesquisa são os problemas comuns que se localizam prioritariamente no seu próprio meio, na comunidade e na região e que exige a leitura interdisciplinar e ação competente dos movimentos sociais. Essa outra universidade que reage a Nova Ordem Mundial e à lógica de mercado defende também a extensão entendida como: processos educativos, culturais e científicos que articula o ensino e a pesquisa de forma indissociável e viabiliza a relação transformadora entre universidade e a sociedade. Essa relação que estabelece a troca de saberes sistematizado, acadêmico e popular, tem como conseqüência: a produção de um conhecimento sobre a realidade brasileira regional; a democratização do conhecimento acadêmico e a participação efetiva da comunidade na atuação da universidade. Nesse contexto este relato apresenta a experiência da Linha de Estudos e Pesquisas em Educação Física \& 


\section{RELATO DE EXPERIÊNCIA Área Temática: Filosofia da Educação}

Esporte e Lazer (LEPEL) da Universidade Federal de Alagoas - UFAL que vem desenvolvendo um processo de construção coletiva que se originou nas aulas de Estudos do Lazer e Recreação Comunitária, utilizando a metodologia participativa com base na “problematização” da realidade encontrada nos espaços de atuação junto às comunidades intra e extras universitárias ${ }^{1}$. Além das atividades desenvolvidas no ensino e na extensão, procurou-se a sistematização de novos conhecimentos, tomando como fonte, tanto os saberes dos participantes como as práticas pedagógicas e sociais que aconteceram durante essas atividades. A “problematização” e a elaboração de questões e perguntas atendendo a critérios de rigor científico permitiram a formulação e o desenvolvimento de dezessete diferentes projetos de pesquisa (trabalhos de conclusão de curso e de iniciação científica, dissertações de mestrado e teses de doutorado) integrando ensino, pesquisa e extensão cujos resultados vêm sendo socializados em diversos eventos científicos em âmbito local, regional e nacional e amplamente aceitos e desenvolvidos pela comunidade local (Maceió) e Estadual (Alagoas) particularmente nos setores mais carentes e excluídos dessa região, considerada dentre as menos privilegiadas no desenvolvimento desigual do Brasil.

\section{EXPERIÊNCIAS GERADORAS}

Duas pesquisas anteriores analisadas criticamente alertaram para a necessidade de uma maior fundamentação teórico-metodológica para compreender e modificar criativamente o ensino e a extensão no contexto da formação profissional e a educação com jovens e adultos. A primeira pesquisa localizada na área do Lazer e Recreação ${ }^{\mathrm{i}}$ analisou junto a Instituições de Ensino Superior as disciplinas acadêmicas em desenvolvimento nos cursos de formação de profissionais de Educação Física e as teorias disponíveis em livros, dissertações, teses, mais utilizadas nessa área. A referida pesquisa permitiu a retomada de conceitos e teorizações e ganhou relevância na media em que ajudou, por um lado, mapear conteúdos mais utilizados na área e, por outro, a elaborar conhecimentos a partir de categorias da prática pedagógica, onde, efetivamente, estão colocados os elementos para uma teorização mais eficiente e plausível. Recuperou-se assim, à relação necessária e contraditória entre a prática e

\footnotetext{
1 Agradecemos à contribuição dos membros da LEPEL/UFAL, Ana Maria Pereira (surtocultural@hotmail.com), Andréa Oliveira (deia_edf@yahoo.com.br), Arizângela Rodrigues, Isabela Valente (isabela.valente@ig.com.br), Francisco Souza (aldrir@bol.com.br), Joelma Albuquerque (joelmaepistefal@yahoo.com.br), $\mathrm{M}^{\mathrm{a}}$ Guadalupe Amorim (lj.anjo@ig.com.br), M da Penha Cavalcante (banfill@universiabrasil.net), Tereza Silva (teka.mrj@pop.com.br) e Thaís Pires (thaissimoes@yahoo.com.br).
} 


\section{RELATO DE EXPERIÊNCIA Área Temática: Filosofia da Educação}

a teoria que permite reconhecer possibilidades e limites no processo de formação de profissionais para atuarem criativamente no campo da Recreação e do Lazer.

Dentre os resultados e recomendações destacamos alguns pontos configurados como novas possibilidades no tratamento epistemológico da Recreação e Lazer, nos currículos de formação de profissional da Educação Física:

1. Trabalhar na perspectiva da revisão da base epistemológica da área;

2. Elaborar o planejamento participativo com base em diagnósticos científicos;

3. Maior sistematização dos conteúdos, visando uma perspectiva teórica mais sólida;

4. Articular ensino, pesquisa e extensão;

5. Aprofundamento na relação dinâmica da teoria e a prática;

6. Articular a pesquisa enquanto elemento fundamental de diagnóstico e prognóstico de possibilidades e propostas alternativas;

7. Rigor no trabalho científico;

8. Avaliação progressiva;

9. O professor além de docente de uma disciplina deve construir a competência como orientador.

Este roteiro coloca em questão os elementos constitutivos do tratamento epistemológico desta área e campo da prática, ou seja, questiona a produção e apropriação do conhecimento no currículo de formação profissional de Educação Física. Indica ainda, que normas e regras constitutivas, regulativas e representativas do trato com o conhecimento passaram a ser indagada criticamente. (CHAVES, 2003, p.128).

Dando prosseguimento a anterior pesquisa um segundo estudo ${ }^{2}$ motivou uma reflexão crítica sobre a relação dialética entre teoria e prática no contexto das experiências de

\footnotetext{
2 Em seus estudos de doutorado, na Faculdade de Educação da Unicamp, desenvolveu a tese sobre A formação profissional em Educação Física \& Esporte: mercado de trabalho $x$ possibilidades históricas emancipatórias, no período de 1994 a 1999. Encontra-se publicada em sua $2^{\text {a }}$ edição uma reflexão crítica
} 
formação profissional que determinada pelos conflitos da sociedade capitalista opõe interesses entre atender ao mercado de trabalho e às exigências históricas da sociedade em processo de emancipação (CHAVES \& SÁNCHEZ GAMBOA, 2003). Com base no pressuposto de que as práticas pedagógicas inseridas nos currículos de formação profissional não se explicam em si mesmas, estas deverão ser compreendidas num projeto de universidade construído através de mediações políticas e institucionais como os projetos pedagógicos, currículos, laboratórios, departamentos, centros, etc., e da relação com a sociedade, nas condições da problemática complexa do Nordeste do Brasil.

A reflexão crítica com base nas experiências concretas de Prática de Ensino permitiu um grau maior de aprofundamento sobre a problemática complexa da formação profissional que se debate entre as necessidades pragmáticas do mercado de trabalho e as possibilidades históricas de formação do professor na perspectiva da emancipação, superando-se a hegemonia do capital e sua lógica utilitarista, possibilitando a ampliação de conhecimentos sobre formação dos professores em seis perspectivas:

1. Compreensão da pesquisa como articulação lógica de procedimentos técnicos, teóricos, metodológicos e de pressupostos epistemológicos em torno de uma perspectiva qualitativa crítica de produção do conhecimento que racionalize a relação conflitiva entre a teoria e a prática na formação profissional;

2. Elaboração de categorias a partir das relações entre trabalho e educação, geradas no registro, sistematização e análise das práticas do ensino;

3. Considerar a prática do ensino enquanto eixo articulador da produção do conhecimento, produzido coletivamente, no exercício da docência;

4. Organizar o processo de trabalho pedagógico, apontando para outras possibilidades históricas de formação - na perspectiva da emancipação;

5. Flexibilização do currículo para atender outras instâncias de formação de professores pedagogia, magistério, a partir da experiência da licenciatura; 


\section{RELATO DE EXPERIÊNCIA Área Temática: Filosofia da Educação}

6. Relacionar a produção coletiva do conhecimento com outras formas de organização do trabalho.

Finalmente constatamos na experiência de uma universidade pública do nordeste brasileiro a possibilidade da construção de um projeto inovador que permitiu recuperar as inter-relações entre a organização do processo de trabalho pedagógico, a formação profissional, a organização social do trabalho e as tendências transformadoras da sociedade. Com base nessa constatação defendemos que a formação do profissional nas universidades não pode estar dissociada dos projetos históricos da sociedade, que o mercado por si só não pode ser um definidor dos parâmetros dessa formação; outros critérios devem ser considerados, especificamente, os relativos às concepções em construção, articulados com os projetos históricos da sociedade, que aponta para uma formação emancipatória e superadora das relações de produção fundadas no trabalho alienado.

Nas duas pesquisas anteriores verificamos a necessidade da fundamentação científica tanto nos níveis metodológico, teórico, como epistemológico que dê suporte à prática pedagógica e à possibilidade concreta da articulação do ensino, da pesquisa e da extensão nos processos de formação profissional.

Na retomada das atividades de ensino com as disciplinas de Estudos do Lazer e Recreação Comunitária, e de extensão com o curso "Vivências no âmbito do lazer e recreação em instituições públicas" foram assimilados os resultados e atendidas as recomendações das pesquisas anteriores. Um novo conceito de universidade foi considerado, entendido como geradora e disseminadora do conhecimento científico na medida em que integra a pesquisa, em todos seus níveis de atuação, inclusive nas disciplinas eletivas e nos cursos de extensão. Especificamente o curso de extensão foi freqüentado por alunos oriundos de diferentes áreas e períodos da UFAL, além de outras instituições. Com base numa metodologia crítico-reflexiva foram utilizados debates e exposições sobre as temáticas de interesse coletivo, assim como seminários, fóruns, leituras, visitas, observações, contando eventualmente com a participação de professores e especialistas convidados. Os participantes do referido curso foram instigados a problematizar, construir coletivamente seus projetos de extensão, e a desenvolverem seus projetos dentro de instituições públicas ${ }^{3}$. Vale ressaltar a dificuldade que muitos desses alunos

\footnotetext{
3 Na realização dos projetos de intervenção foram integrados membros das comunidades e das escolas circunvizinhas.
} 


\title{
RELATO DE EXPERIÊNCIA Área Temática: Filosofia da Educação
}

tiveram para sistematizar o conhecimento e acompanharem o ritmo de leituras, pois os mesmos não consideravam importante tal atividade para essa área do conhecimento.

\section{Conforme podemos verificar nos relatórios individuais os participantes} expressaram as dificuldades encontradas, apontando propostas para solução das mesmas. Como exemplo, citaremos algumas delas:

\begin{abstract}
"Espantei com a metodologia utilizada, achei que poderia não cumprir todas as atividades. Mas, com o decorrer das aulas, o pensamento de desistência deu lugar ao empenho de realizar cada tarefa. Cheguei a apresentar trabalho no VII EREEF e Mostra Científica do DEF/UFAL, em forma de painel - uma vitória para quem está no $1^{\circ}$ ano. Foi uma turma que começou grande, mas que alguns assustados foram desistindo, devido à proposta de trabalho, que até então não havia sido experimentada por nós, afinal, como acadêmica de $4^{\circ}$ ano também não tinha trabalhado na metodologia que a professora nos apresentava e nos desafiava. Aos que aceitaram o desafio restou uma grande conquista, pois nos foram oferecidas inúmeras experiências na construção da nossa formação.”
\end{abstract}

Como propostas para solução das dificuldades foram destacados pelos participantes dos cursos alguns itens:

\begin{abstract}
"Para que os alunos obtenham mais experiências na área do Lazer/Recreação é necessário que os mesmos tenham contato com atividades práticas a partir do primeiro ano de curso, inicialmente observando a prática pedagógica e ao mesmo tempo construindo um projeto de pesquisa com o acompanhamento dos professores do curso ao longo de sua formação acadêmica. Mais incentivo ao aluno para trabalhar no âmbito do ensino-pesquisa-extensão nas demais disciplinas. Estímulo para que sejam aprofundados os estudos durante o ano letivo, tendo como resultado a apresentação de trabalhos em eventos científicos; Trabalhar integrado com outras instituições do Estado; Procurar financiamento para o desenvolvimento dos projetos."
\end{abstract}

Alguns dos destaques a serem considerados foram: a) a motivação para a criação da Linha de Estudos e Pesquisas em Educação Física \& Esporte e Lazer na UFAL; b) o aprendizado da metodologia científica na forma do método de pesquisa e do método de exposição; c) a continuidade de alguns projetos que ultrapassaram os limites de sala de aula, os períodos eletivos, as dificuldades de recursos financeiros e de apoio institucional conforme poderemos verificar no item de resultados; d) a produção de novos projetos encaminhados às pró-reitorias de Extensão (PROEX) e de Pesquisa e Pós-Graduação (PROPEP) nos programas PIBIC/CNPq, ou como Trabalhos de Conclusão de Curso, e mesmo como projeto de dissertação de mestrado; e, e) a participação permanente em todos esses projetos de representantes das comunidades circunvizinhas tanto na sua discussão como na sua realização e avaliação. 


\section{RELATO DE EXPERIÊNCIA Área Temática: Filosofia da Educação}

Com base nessas experiências geradoras, nos resultados e na avaliação das dificuldades, das motivações e dos compromissos, os novos projetos foram desenvolvidos, munidos de uma reflexão aprofundada sobre a concepção de universidade e suas relações com a sociedade e de uma orientação científica mais apurada em torno da problematização tida como ponto de partida da produção do conhecimento e base do método científico, entendido como mediação que qualifica o conhecimento e o diagnóstico dos problemas permite a organização e disseminação de resultados. Conhecimentos e diagnósticos que se tornam válidos na medida em que são apropriados como critérios da ação transformadora da realidade, em razão da tese de conhecer para transformar. Tanto a nova concepção de universidade como a concepção de problematização explicita a seguir.

\section{NÚCLEOS DE REFERÊNCIAS}

Entendemos como núcleos de referência um grupo de categorias que oferecem um horizonte compreensivo tanto para prática da pesquisa como para a interpretação e validação dos resultados. Esses núcleos funcionam como premissas operativas que orientam e qualificam os projetos de ensino, pesquisa e extensão. Dado seu caráter abrangente oferecem de forma plausível recursos para situar os problemas, definirem objetivos e estratégias de pesquisa. Entendemos que esses núcleos de referência podem ser múltiplos e variados e podem ser multiplicados na medida em que se avança nas sistematizações e se relacionam os processos e os resultados em quadros teóricos mais amplos e complexos. Entretanto, para manter coerência com a dinâmica da constituição da LEPEL, inicialmente foram destacados os dois núcleos de referência acima anunciados, concepção de universidade e o conceito básico de problematização como fonte do processo de pesquisa ${ }^{4}$.

\subsection{Conceito de universidade}

As discussões giraram sobre as condições histórico-sociais da universidade que desde seus primórdios no século XII, como corporações de estudantes, (Universitas Scholarium, Bolonha, 1.110) ou como corporações de professores (Universitas Magistrarum,

\footnotetext{
${ }^{4}$ Outro núcleo de referência já utilizado nas pesquisas da LEPEL é a relação dialética entre teoria e prática. Remetemos ao leitor para duas publicações dos membros do grupo que desenvolvem essa temática, SÁNCHEZ GAMBOA. S. Teoria e Prática: Uma relação dinâmica e contraditória. In: Motri-vivência, Florianópolis, ano 6. n. 8, dezembro 1995, pp. 8-20 e SÁNCHEZ GAMBOA, S; CHAVES, M. Prática de Ensino: formação profissional e emancipação, Maceió: Editora UFAL, 2003 ( $2^{\mathrm{a}}$ ed.).
} 


\section{RELATO DE EXPERIÊNCIA Área Temática: Filosofia da Educação}

Paris, 1.150$)^{5}$ se atrelaram à dinâmica da sociedade e dependendo da conjuntura política reproduzem os interesses e ideologias dominantes como os conflitos sociais e os processos de superação desses conflitos. Na medida em que foi desenvolvendo novas funções além do ensino de saberes específicos: do Direito (Bolonha), da Filosofia e Teologia (Paris) e das Ciências Naturais (Oxford). Como instituição sociocultural, com papéis definidos em função das necessidades da sociedade e da produção de conhecimentos novos (Universidade de Berlim no século XIX) e como prestadora de serviço (Estados Unidos século XIX) ou disseminadora de conhecimentos técnicos (Universidades populares na Europa, também século XIX) nessa medida ganha influência nas populações e suas relações se tornam mais complexas e suas funções tradicionais de ensino, pesquisa e extensão ganham novas abordagens.

No contexto atual da universidade brasileira o debate sobre essas funções básicas ganha um novo patamar a partir da recente legislação que com o intuito de facilitar a expansão da matrícula com a implementação de centros universitários, faculdades integradas, faculdades e institutos superiores ou escolas superiores (Decreto No 2.306 de 1997, Art. 8º) alterou o paradigma de ensino superior antes centrado na universidade pública. A nova legislação facilita as atividades de ensino dissociadas da pesquisa e a extensão e mantém a obrigatoriedade da indissociabilidade apenas para as universidades, modificando o paradigma do ensino superior e abrindo espaço jurídico para que outras instituições, de fato, se torne o modelo predominante. Essas instituições abrangem, não apenas um percentual maior da matrícula do ensino superior (75\%), mas servem de critério para os planos de desenvolvimento do setor e das políticas que pretendem superar o pesado déficit acumulado do baixo índice de escolaridade superior. Índice que se torna ainda mais pesado se comparado com os países industrializados, e significativamente mais gritante no quadro dos países da América Latina, onde o Brasil, apesar dessas políticas facilitadoras e empobrecedoras da Educação superior, continua num penúltimo lugar pouco confortável superando apenas a Nicarágua (Cf. TRINDADE, Cf. 1997, p. 50).

Outras medidas nefastas foram recentemente estabelecidas para desmontar o princípio da indissociabilidade. Segundo Taffarel (2002, p.2):

\footnotetext{
${ }^{5}$ A corporação era freqüentemente chamada universitas (VERGER, 1990:27). Tanto a "Universitas Scholarium", quanto a "Universitas Magistrarum", foram organizadas em função dos estudos gerais "Studia Generalia" ou "Universitas Studiorum". Decorria daí a denominação simplificada de universidade. (Cf. VERGER, Jacques. As Universidades na Idade Média, 1990: 55 e 71).
} 


\title{
RELATO DE EXPERIÊNCIA Área Temática: Filosofia da Educação
}

\begin{abstract}
"Analisando os Programas que o Governo vem propondo as Universidades, como o PRONEX (Programa de Apoio a Núcleos de Excelência), a GED e GID (Gratificações de estímulo ou Incentivo a docência), o PNG (Programa Nacional da Graduação e as Diretrizes para o Ensino), a famigerada Lei Orgânica da Universidade que desconstitucionaliza o Artigo 207 que trata da Autonomia Universitária, a Lei de Inovação Tecnológica, entre outras iniciativas, reconhecemos os indicadores da estratégia do governo que é estabelecer a dissociação entre ensino, pesquisa e extensão, a separação entre as próprias Universidades - de ensino, de pesquisa, de extensão -, concentração de pesquisa em centros de excelência, com alta performance de qualidade e produtividade e, gestão flexível de recursos humanos vinculados a projetos específicos, desistintucionalizando recursos e pesquisadores, abrindo o caminho acelerado à privatização, 'sintonizando a Universidade com a Nova ordem Mundial, a lógica do mercado', cooptando a subjetividades e assaltando as consciências dos professores e alunos.”
\end{abstract}

Entretanto tem outra universidade que reage contra a destruição insistindo no princípio da indissociabilidade entre ensino-pesquisa-extensão e na formação de intelectuais orgânicos. É a universidade que constrói sua identidade gerando um conhecimento exaustivo da problemática da sociedade onde atua, recuperando e conservando nos arquivos bibliotecas, museus e centros de documentação as informações e registros já produzidos do modo mais universal possível, sobre todos os aspectos da região e dos fenômenos que nela acontecem. Assim a universidade estará vocacionada a se tornar o centro do conhecimento sistematizado sobre a realidade, oferecendo fontes para a construção de novos conhecimentos, para a formulação de projetos de investigação e para o desenvolvimento de um ensino que responda às necessidades e as exigências da sociedade e contribua com os projetos históricos e perspectivas de transformação da mesma.

Essa outra universidade hoje se organiza em grupos de pesquisa dedicados a sistematizarem informações e gerarem massa crítica sobre a problemática da sociedade onde atuam, na medida em que suas investigações tomam como base as questões mais prementes da comunidade, interrogam criticamente o atual estado de coisas, refletem e polemizam sobre os variados aspectos da vida e da dinâmica histórica dessa sociedade. O eixo aglutinador dos grupos ou núcleos de pesquisa são os problemas comuns que exige a leitura interdisciplinar e ação competente dos pesquisadores. Esses problemas que desafiam a criatividade dos grupos de pesquisa localizam-se prioritariamente no seu próprio meio, na comunidade, na região e para os quais não poderão fechar os olhos, sob pena de se estar gerando pesquisa acadêmica ritualizada, sem relevância social e longe do critério básico da significação científica de “conhecer para transformar”. Essa outra universidade que reage a Nova Ordem Mundial e à lógica de mercado defende a extensão entendida como: 


\title{
RELATO DE EXPERIÊNCIA Área Temática: Filosofia da Educação
}

\begin{abstract}
"Processos educativos, culturais e científicos que articula o ensino e a pesquisa de forma indissociável e viabiliza a relação transformadora entre universidade e a sociedade. A extensão é uma via de mão dupla, com trânsito assegurado à comunidade acadêmica que encontrará a sociedade, a oportunidade de elaboração da práxis de um conhecimento acadêmico. No retorno à universidade, docentes e discentes trarão um aprendizado que, submetido à reflexão teórica, será associado aquele conhecimento. Este fluxo que estabelece a troca de saberes sistematizado, acadêmico e popular, terá como conseqüência: a produção de conhecimento resultante do confronto com a realidade brasileira regional; a democratização do conhecimento acadêmico e a participação efetiva da comunidade na atuação da universidade.” (I Forum Nacional de Pró-Reitores de Extensão de Universidades Públicas, BRASIL, MEC, 1987, p.1 apud MELO NETO, 2002, p. 23).
\end{abstract}

Essa outra universidade solidária que vem superando as concepções equivocadas de extensão e trabalhando com a sociedade de forma criativa e transformadora num processo de dupla mão entre universidade e comunidade entre prática e teoria num devir dialético’ onde a crítica como constituinte do agir permite a superação do "senso comum" e imprimir um caráter transformador à ação coletiva ${ }^{6}$. Nesse sentido Melo Neto (2002, p.28) afirma:

\begin{abstract}
"A extensão em sendo trabalho social sobre a realidade objetiva, gerado de um produto em parceria com a comunidade, a esta comunidade deverá retornar o resultado dessa atividade de extensão. Essa é outra dimensão fundamental caracterizada como a devolução de suas análises da realidade objetiva à própria comunidade. A devolução dos resultados do trabalho social à comunidade caracterizará a própria comunidade como possuidora de novos saberes ou saberes rediscutidos e que serão utilizados pelas diferenças comunitárias em seus movimentos emancipatórios e reivindicatórios. Isso faz crer a extensão exercendo e assumindo uma dimensão filosófica fundamental, que é a busca de superação da dicotomia teoria e prática. Estas, também, se constituem como bases ontológicas da extensão.”
\end{abstract}

Dessa forma a extensão entendida como trabalho social é exercida coletivamente por sujeitos vinculados à universidade e à comunidade num processo de conhecimento e ação sobre a realidade objetiva. Nessa perspectiva, é possível um processo educativo, científico, técnico e cultural que se articula com o ensino e a pesquisa em forma indissociável no contexto das relações dinâmicas e transformadoras entre universidade e sociedade.

A perspectiva crítico-dialética como uma forma de abordar a extensão e as relações entre universidade e sociedade inicia-se com a problematização e com o olhar crítico sobre a realidade, onde a suspeita, a dúvida, a curiosidade a indagação, a questão e a pergunta se tornam pontos de partida do conhecimento da realidade. Esse olhar crítico poderá

\footnotetext{
${ }^{6}$ As concepções equivocadas de Extensão tais como prestação ser serviço, assistencialismo e controle social, captação de recursos externos ou como qualquer outra atividade diferente ao ensino e a pesquisa.
} 


\section{RELATO DE EXPERIÊNCIA Área Temática: Filosofia da Educação}

diferenciar os verdadeiros problemas dos pseudoproblemas que segundo SAVIANI (2000) implica problematizar o problema superando as aparências (pseudo concreticidade) e captando, via as reflexões radicais, rigorosas e de conjunto as necessidades que se impões objetiva e subjetivamente e que não se soluciona apenas com a informação simples já elaborada ou codificada num dicionário, texto ou arquivo na internet. O verdadeiro problema não se identifica com o "não saber", ele se apresenta como obstáculo, dificuldade, conflito, dúvida, crise para o qual não tem resposta pronta. Daí, a necessidade e o desafio de um processo de conhecimento para elaborar respostas novas e pertinentes a concreticidade do problema (Cf. KOSIK, 1976). Daí a importância do método científico que instrumentaliza a relação dialética entre pergunta e resposta entre a realidade problemática e a sua transformação.

\subsection{A Problematização}

Com base na premissa anterior podemos ampliar a discussão sobre as estratégias e as ações necessárias para a consolidação da universidade compromissada com a produção e disseminação dos conhecimentos científicos, atrelados ao desenvolvimento das regiões e comunidades onde se situam e se desenvolvem. Toda estratégia de implementação da pesquisa e da extensão e de consolidação de um projeto de universidade que não apenas consuma ou reproduza saberes e informações científicas, mas gere conhecimentos relevantes sobre os problemas concretos da sociedade, deverá se pautar pelas concepções básicas da pesquisa científica.

Retomar os fundamentos da pesquisa científica implica definir como base do processo a localização, identificação e formulação do problema e a tradução deste num quadro de questões orientadoras das buscas, articuladas em torno de uma pergunta central. Processo que denominado de problematização.

Toda pesquisa científica obedece ao protocolo básico, embora complexo, da elaboração de uma pergunta qualificada sobre uma problemática concreta e da procura de respostas disciplinadas para essa pergunta. 


\section{RELATO DE EXPERIÊNCIA Área Temática: Filosofia da Educação}

"El problema constituye el eje central de toda investigación. Todo proyecto de investigación expresa fundamentalmente un problema, cuestiones sobre ese problema y la formulación de una pregunta-síntesis. En forma de síntesis, podemos decir que el esquema básico del proceso de investigación es el mismo de la relación entre pregunta y respuesta.

P REGUNTA RES P UES T A

Y el esquema básico de un proyecto de investigación puede ser simplificado en la relación básica de una pregunta cualificada y pertinente sobre una problemática y algunos indicadores sobre la posible respuesta a esa pregunta. Y los relatorios de investigación, deben obedecer al esquema básico del montaje de la respuesta. (...) Una vez realizada la investigación, las soluciones, los resultados, la interpretación de los mismos, así como la respuesta, su significado y pertinencia serán presentadas en un relatorio, o en un cuerpo informativo de una tesis de maestría, doctorado, etc." (SÁNCHEZ GAMBOA, 1998, p. 87).

Mas, onde encontrar os problemas geradores das pesquisas? O que perguntar? Quais as questões geradoras de pesquisa? Onde localizar a problemática com base na qual seja possível elaborar as questões e perguntas que nortearão a busca de respostas? Onde encontrar os problemas fonte de interrogantes e indagações a partir dos quais serão elaborados os projetos de investigação e as atividades dos grupos de pesquisa?

A resposta poderá ser simples: na realidade concreta da sociedade onde a universidade finca sua ação. Daí porque qualquer estratégia de construção de universidade deverá se pautar pela necessidade do conhecimento exaustivo da problemática da comunidade na qual se situa. E como ter acesso a essa problemática? Através da mão dupla do devir entre as comunidades e a universidade e através de processo de extensão do trabalho social crítico, indagador e curioso dos sujeitos que se educam pesquisam e interagem coletivamente.

A investigação ou pesquisa é um processo metódico que equivale a buscar algo a partir de vestígios ou de pistas. É uma forma de elaborar respostas rigorosas e sistemáticas para as indagações sobre a realidade.

Podemos dividir a metodologia científica em duas partes a primeira relacionada com a elaboração da pergunta e a segunda relacionada com a elaboração da resposta: a primeira deve apresentar a articulação entre o problema, seus indicadores, as questões e a pergunta e, a segunda, relativa a previsão das formas da elaboração da resposta.

Toda pesquisa surge de uma situação problema. Pesquisamos quando surge a suspeita, a dúvida, a necessidade, o conflito, a crise. Para que a pesquisa se torne um processo 


\section{RELATO DE EXPERIÊNCIA Área Temática: Filosofia da Educação}

concreto, precisamos localizar o campo problemático. Essa primeira fase é denominada de “situação problema”. Sobre essa situação concreta elaboramos um primeiro levantamento para identificar os indicadores ou "sintomas” do problema. Essa busca pode ser acompanhada de uma revisão sobre antecedentes sobre o problema em questão, ou sobre pesquisas que tenham abordado a mesma problemática.

Uma vez localizado o problema num contexto específico e identificado seus indicadores, é necessário traduzir essa problemática num corpo de questões na forma de proposições interrogativas. Essas questões vão orientar as buscas e o processo de elaboração das respostas. Entretanto, devem ter um ordenamento lógico em torno de uma pergunta síntese que articula e dá sentido às questões aparentemente desconexas ou referidas a várias pesquisas sobre o mesmo problema. Uma vez colocada à pergunta, o projeto deve prever, os processos da elaboração da resposta.

Essa segunda parte da metodologia se refere às fontes onde poderemos obter informações para elaborar a resposta. As fontes referem-se também às tentativas de localizar a resposta perguntando-se: "Onde poderia ter respostas a estas perguntas?". A metodologia também deverá considerar os instrumentos e técnicas para coletar e organizar as informações, as formas de análise dessas informações e as maneiras de interpretar os resultados à luz de categorias e quadros teóricos.

A elaboração da resposta às perguntas, atrelada ao problema, exige a apropriação e o aprimoramento do método científico e de referenciais teórico-epistemológicos que permitam a articulação lógica dos elementos da construção do conhecimento e delimitação de um horizonte para a interpretação dos resultados. Esse processo de teorização terá a sua validade assegurada na medida em que a relação com a prática está assegurada isto é, quando a forma de abordar e diagnosticar o problema também oferece recursos interpretativos e compreensivos que levam a intervenção transformadora da realidade problematizada. Nem todas as abordagens científicas permitem essa relação dialética entre diagnóstico e intervenção, entre teoria e prática entre pesquisa e trabalho social e entre conhecer e transformar (cf. Marx, Teses sobre Feuerbach. In: MARX e ENGELS, 1981). Daí a importância das opções epistemológicas e a explicitação dos interesses que orientam o conhecimento ${ }^{7}$.

\footnotetext{
${ }^{7}$ O leitor pode ampliar essa discussão sobre o conflito dos paradigmas científicos na pesquisa em Sánchez Gamboa (1996) e em Habermas (1982).
} 


\section{RELATO DE EXPERIÊNCIA Área Temática: Filosofia da Educação}

\section{PRINCIPAIS RESULTADOS DO PROCESSO COLETIVO}

Uma vez explicitadas as experiências geradoras que motivaram e propiciaram as circunstâncias para o desenvolvimento das atividades de extensão articuladas com o ensino e a pesquisa e a consolidação do grupo de estudos e pesquisa LEPEL e depois de explanar as referências sobre a concepção de universidade e a problematização como ponto de partida tanto dos projetos de extensão, de pesquisa e as práticas pedagógicas e sociais, apresentamos a seguir a descrição sucinta dos principais projetos desenvolvidos com o suporte do grupo de estudos e pesquisas LEPEL.

A Linha de Estudos e Pesquisa em Educação Física \& Esporte e Lazer (LEPEL), embora localizada inicialmente nessa área de formação profissional, hoje tem uma dimensão interdisciplinar e abrange diversos projetos, integrados em torno de uma pesquisa matricial e que conta com a participação de diferentes sujeitos políticos motivados por uma formação profissional que atenda às necessidades prementes dos setores mais desfavorecidos da sociedade e considere os projetos históricos que superem as relações econômicas de exploração da formação social capitalista.

A LEPEL tem como objeto de estudo a Cultura Corporal e desenvolve projetos de ensino-pesquisa-extensão, contribuindo na formação profissional, na produção do conhecimento científico da área, na qualidade das intervenções profissionais e na elaboração e crítica de políticas públicas. Está inscrita no Diretóro Nacional dos Grupos de Pesquisa no Brasil - CNPQ enquanto Grupo de Pesquisa - LEPEL da Faculdade de Educação da UFBA, e do Departamento de Educação Física da UFAL.

Dentre as atividades da LEPEL/UFAL está o núcleo temático "Problemáticas Significativas do Trabalho Pedagógico no Campo do Lazer", que no período de 2000 a 2003 desenvolveu vários projetos de extensão e de TCCs, conforme podemos relacionar a seguir ${ }^{8}$ :

1. Vivências no âmbito de lazer/lazer em instituições públicas - agosto de 2000 a janeiro de 2001;

8 Esse núcleo temático decidiu coletivamente desenvolver o seguinte problema: "É possível desenvolver experiências de formação e intervenção profissional que atendam à produção do conhecimento e às possibilidades históricas emancipatórias da sociedade no curso de educação física da UFAL?" 
2. Festival Lúdico Cultural - janeiro e fevereiro de $2001^{9}$;

3. Projeto de Extensão Santa Lúcia: ações, saúde coletiva comunitária, Educação Física interferindo no processo de transformação social na comunidade através do desporto, recreação/lazer - 2000 - 2001;

4. Lazer Especial - abril de $2001^{10}$;

5. O turismo e o lazer unidos para uma integração social ${ }^{11}$ - 2001;

6. Recreação, Lazer e Cultura no R.U. como forma de transformação - 2001;

7. O teatro como forma de educação e integração entre o núcleo de apicultura do Instituto Xingó, a comunidade e o turismo - 2001-2002 ${ }^{12}$;

8. Problemáticas significativas da profissionalização precoce do estudante em formação inicial no curso de Educação Física da UFAL - $2001^{13}$;

${ }^{9}$ Como propostas para solução das dificuldades, os participantes destacaram: "Uma das possibilidades de desenvolvimento das atividades integradas foi o trabalho desenvolvido durante todo o curso no segundo semestre de 2000, envolvendo a comunidade com atividades de integração"; - "Trabalhar Oficinas com atividades variadas visando à participação de diferentes clientelas"; - "Possibilidade de participação de alunos do curso de Educação Física de outros períodos, participantes ou não do curso de extensão"; - "Trabalhar em Oficinas, deixando a clientela com várias opções para escolha de sua participação nas atividades"; "Importância do trabalho integrado de extensão, com o ensino e a pesquisa"; - "Foi considerado como positivo a construção coletiva do Festival de Encerramento do Curso de Extensão"; - "Que sempre eventos dessa natureza tenham maior apoio efetivo de toda UFAL, porque é um espaço considerado muito rico para integrar o aluno com a comunidade em geral"; - "Importância de contar com a monitoria de uma aluna experiente e trabalhar na perspectiva integrada".

${ }^{10}$ Este projeto foi desenvolvido integrado a SEMED/DEFD/ Comissão Técnica da Secretaria Municipal de Saúde/AL. Destacamos as propostas para solução das dificuldades emitidas pelos participantes do projeto: "Que outros eventos possam acontecer com este intuito, integrar grupos discriminados pela sociedade, e que nós da universidade possamos participar e dar nossa parcela de contribuição para a socialização de todos"; "Essa experiência foi de extrema importância para nós acadêmicos de Educação Física, pois além de termos tido a oportunidade de vivenciar uma atividade que havia sido programada para os deficientes, tivemos contato direto com algumas dificuldades dos mesmos"; - "Embora não tivéssemos preparadas a receber um grupo de pessoas de idade tida como avançada, já que preparamos previamente um trabalho para deficientes, a integração grupal foi amplamente satisfatória, superando nossas expectativas. Dessa forma, os objetivos foram atingidos";

${ }^{11}$ O projeto surgiu a partir da disciplina Estudo do Lazer com o objetivo de "Promover a integração através da Recreação/Lazer entre crianças, jovens adultos e idosos", procurou desenvolver o problema: "Quais as problemáticas significativas da prática pedagógica no campo do lazer e turismo na formação inicial de estudantes de educação física da UFAL, em Xingó, para integração social entre crianças, jovens, adultos e idosos?”

${ }^{12}$ Este projeto desenvolveu o seguinte problema: "Quais as problemáticas significativas na prática pedagógica no campo de teatro-educação na formação continuada de estudantes do Curso de Artes Cênicas da UFAL, que possibilitem introduzir as técnicas teatrais nas atividades agropastores, que beneficiem a comunidade na utilização racional de recursos disponíveis no Programa de Xingó durante o período de 2001 - 2002"?

${ }^{13}$ Este projeto também foi apresentado pelo acadêmico Edson André da Rocha Daniel como Trabalho de 
9. Atividades recreativas para crianças portadoras de Leishmaniose Visceral - $2001^{14}$;

10. Brincando como antigamente $-2002^{15}$;

11. Surto Cultural - 2002-2003 ${ }^{16}$;

12. Recrear Criando ${ }^{17}$.

Podemos destacar ainda como um dos resultados da proposta desenvolvida nas atividades de extensão relatadas anteriormente, a disseminação de outros grupos não só na

Conclusão no Curso de Educação Física da UFAL.

${ }^{14}$ Este projeto foi registrado também na PROEX e também foi desenvolvido pela acadêmica Andreia Lins Peixoto como trabalho de Conclusão do Curso de Educação Física da UFAL.

${ }^{15}$ O Projeto "BRINCANDO COMO ANTIGAMENTE" foi desenvolvido pelas disciplinas: Estudos do Lazer, Recreação Comunitária e Educação Física Escolar, no período de 25 de janeiro a 05 de abril de 2002; "BRINCANDO COMO ANTIGAMENTE: uma possibilidade de integração", desenvolvido junto às disciplinas Estudos do Lazer e Recreação comunitária de 19 de junho a 14 de julho de 2002, e, "BRINCANDO COMO ANTIGAMENTE: uma possibilidade de integração com a comunidade", desenvolvido pela LEPEL/UFAL nos meses de novembro e dezembro de 2002. Este projeto foi realizado com sucesso, fornecendo um grande conhecimento prático pedagógico, como também interação, sociabilização e lazer de um modo salutar, instigando o grupo para desenvolver outros projetos que viessem a enriquecer a prática didática. Devido ao grande êxito do projeto financiado pela PROEX, foi dada continuidade junto ao Projeto Domingo no Campus, realizado uma vez por mês e organizado pela Pró-Reitoria de Extensão (PROEX/UFAL).

${ }^{16}$ O Projeto "SURTO CULTURAL" surgiu como iniciativa de estudantes da Universidade Federal de Alagoas. Hoje, fazem parte da sua equipe, acadêmicos dos cursos de Artes Cênicas, Música, Educação Física e estudantes voluntários, tendo uma Assistente Social - Ana Maria Pereira, como Coordenadora. Atualmente encontra-se ligado a uma Linha de Pesquisa Interdisciplinar e as Pró-Reitorias de Extensão e Estudantil. Tem o objetivo proporcionar um espaço de divulgação da cultura alagoana em suas diversas modalidades. Para tanto, desenvolve oficinas de teatro, música, circense e apresentações folclóricas, musicais, teatrais no Campus da UFAL. Estando dessa forma, divulgando, dinamizando e sensibilizando a Comunidade Universitária e Sociedade Civil sobre a importância da arte enquanto instrumento de afirmação cultural. Este projeto alcançou os seguintes resultados: - Sensibilização da comunidade acadêmica e artistas alagoanos no sentido de qualificar as apresentações culturais no Campus da UFAL; - Intercâmbio entre Comunidade Universitária e Sociedade Civil; - Realização de atividades de caráter interdisciplinar que possibilitou a integração de alunos (as) de vários cursos e sociedade; - Fortalecimento do Movimento Cultural na Universidade; - Envolvimento, reconhecimento e comprometimento de artistas alagoanos em participar das atividades; - Transformação do Restaurante Universitário em um espaço de integração, sociabilidade e diversão; Formação de 18 alunos no curso básico de violão; Capacitação de alunos, funcionários e filhos de funcionários em criar e produzir máscaras carnavalescas em papel marchê, através do curso produção de máscaras; - Capacitação em promoção de saúde para alunos dos cursos de Serviço Social, Nutrição, Psicologia e Enfermagem; e, capacitação de alunos e pessoas da comunidade civil em produzir peças em argila.

${ }^{17}$ O projeto "RECREAR CRIANDO" situa-se no âmbito de discussão sobre a intervenção do futuro profissional dos diversos cursos do Centro de Ciências da Saúde (Educação Física, Medicina, Enfermagem, Odontologia, Nutrição), que estão desenvolvendo trabalhos com a comunidade vicinal da UFAL, e com a possibilidade de desenvolvimento de projetos integrando o ensino, a pesquisa e a extensão. O referido projeto tem o objetivo geral: - orientar a formação de acadêmicos dos diversos cursos da UFAL, a intervirem em projetos de extensão e de pesquisa que desenvolvam atividades e brincadeiras populares em extinção junto à comunidade vicinal, com base no resgate da experiência acumulada, dentro do Projeto Domingo no Campus. 
UFAL como em outras instituições de ensino pelos membros participantes daquelas atividades $^{18}$.

Além das anteriores atividades, a LEPEL/UFAL desenvolve outros projetos temáticos ${ }^{19}$, dentre os quais destacamos o núcleo EPISTEF (Epistemologia da Educação Física) que aborda as problemáticas significativas da produção do conhecimento científico da área.

O núcleo temático EPISTEF desenvolve o subprojeto de pesquisa: “A produção de pesquisas em Educação Física no mordeste brasileiro (Estados de Alagoas, Bahia, Pernambuco e Sergipe)", com financiamento de bolsa PIBIC/CNPq. Esse projeto se justifica no significativo trabalho dos pesquisadores, docentes das Instituições de Ensino Superior (IES) sediadas na região que, embora sem ter cursos de pós-graduação Latu Senso, vem elaborando uma importante produção, que permite a formação de uma significativa massa crítica sobre a problemática da Educação Física na região. Esta pesquisa elaborou um levantamento dessa produção, analisando as problemáticas abordadas, as formas de tratamento teórico-metodológico, as tendências epistemológicas, as propostas pedagógicas,

\footnotetext{
${ }^{18}$ Isabela Valente, estudante de fisioterapia na Faculdade de Alagoas, participou das atividades de Metodologia Científica e desenvolve junto com outras colegas e professores dois projetos: o primeiro projeto surgido na disciplina de Fundamentos da Fisioterapia, "PEZINHO DA ALEGRIA". O grupo destaca a seguinte problemática: "Qual a incidência de crianças de 2 a 7 anos com pé chato na vila dos pescadores no bairro do Jaraguá/Maceió, de maio a julho de 2003? O trabalho é desenvolvido com o intuito preventivo e visa integrar pessoas da comunidade num trabalho coletivo, e vai prosseguir no próximo semestre. Os resultados foram socializados e contou com apoio dos professores e coordenadora e direção da faculdade. O segundo "PROJETO MELHOR DE BEM VIVER", desenvolve estudos junto a setenta idosos da Casa dos Pobres de Maceió e pretende investigar o seguinte problema: "Como a Fisioterapia dentro de seus limites acadêmicos poderá contribuir para a qualidade de vida dos idosos da casa dos pobres de Maceió? O grupo desenvolve pesquisa bibliográfica e de campo, observação junto aos idosos, além de utilizar questionário para obter dados para analisarem os dados. As aplicações de programas fisioterápicos são desenvolvidas segundo o nível de conhecimento dos pesquisadores, fundamentalmente com a supervisão do docente. Esta mesma pesquisadora pretende desenvolver seu TCCs, questionando sobre a produção dos profissionais da área.

${ }^{19}$ A formação do grupo LEPEL/UFAL (Linha de Estudos e Pesquisa em Educação Física \& Esportes e Lazer) está ligada ao grupo da LEPEL-FACED/UFBA, desde fevereiro de 2000 (Convênio UFAL/UFBA), e vem participando na intensificação da rede regional de intercâmbio interinstitucional e na elaboração conjunta de eventos científicos em nível Regional e Nacional. O grupo de pesquisa está redimensionando o processo de trabalho pedagógico e de produção do conhecimento, considerando a pesquisa como princípio educativo, buscando intensificar as inter-relações entre pessoas e instituições, de forma interativa, produtiva e solidária e através de concepção de Pesquisa Matricial (Pesquisa-Ação) na qual estão articulados projetos, tanto de iniciação científica da graduação, quanto do programa de pós-graduação. Articula-se em torno de projetos para responder as demandas, reivindicações e necessidades históricas postas no Nordeste do Brasil. A LEPEL/UFAL diversifica seus interesses em cinco núcleos temáticos: 1. Problemáticas significativas no campo da cultura corporal - a formação inicial e continuada, a produção do conhecimento científico da área, a intervenção profissional nos campos de trabalho em expansão e, as políticas públicas; 2. Atividade Física e Saúde; 3. Problemáticas significativas do processo de interação social na educação física adaptada; 4. Problemáticas significativas do trabalho pedagógico no campo do lazer; e, 5. História da Educação Física e dos Desportos (em formação).
} 


\section{RELATO DE EXPERIÊNCIA Área Temática: Filosofia da Educação}

sociais e políticas superadoras das problemáticas analisadas e os compromissos regionais

delineados e anunciados nessas pesquisas. Espera-se que os resultados desse balanço crítico da produção na região permitiram definir estratégias de implementação de novos estudos e implantação e desenvolvimento de novas linhas de pesquisa ${ }^{20}$. Como resultado imediato dessa pesquisa foram encaminhados os projetos de iniciação científica (PIBIC) e trabalhos de Conclusão de Curso (TCCs) que analisam tópicos específicos dessa produção, visando uma maior compreensão teórica dos fundamentos da Educação Física, levando em consideração os conhecimentos acumulados na referida pesquisa da LEPEL ${ }^{21}$..Dentro do grupo podemos ainda reconhecer a participação de uma pesquisadora graduada em Serviço Social que atualmente desenvolve um projeto, visando os estudos de pós-graduação ${ }^{22}$.

${ }^{20}$ A execução do projeto coordenada pela Professora Dra Márcia Chaves, coordenadora da linha de pesquisa
LEPEL/UFAL com assessoria da Professora Dra Celi Taffarel (Titular da Faculdade de Educação da UFBA e
Coordenadora da linha de pesquisa LEPEL/UFBA) e do Prof. Dr. Silvio Sánchez Gamboa (Professor Visitante da
UNICAMP nas Universidades Federais de Alagoas e Bahia) e especialista em epistemologia da pesquisa.
Especificamente na UFAL e a participação das acadêmicas de Educação Física Tereza Izabel Pereira de Melo
Silva, Andréa Flávia Santos de Oliveira e Joelma de Oliveira Albuquerque.
Tereza de Melo Silva partiu da pesquisa acima citada, destacou a "Concepção de Educação Física e de Homem/Sociedade", construindo assim, um projeto de pesquisa interligado, onde pretende investigar: "Quais as concepções de Educação Física e Homem/Sociedade mais enfatizadas nas produções científicas (Ms. e Dr.) do nordeste brasileiro (AL, PE, BA e SE), de 1982 a 2002?" Inserido em um projeto maior, em que espera-se como resultado ter um balanço crítico dessas produções na região que permitirá definir estratégias de implementação de novos estudos relacionados com a formação de educadores e pesquisadores no nordeste brasileiro e assim influenciam na discussão sobre a prática dos novos profissionais, tendo, ou não, a Educação Física como meio de transformação social (Homem/Sociedade), pois até os dias atuais, a Educação Física tem atuado de forma aleatória, adaptando o homem a uma sociedade que defende os interesses da classe que detém o poder.

Andréa de Oliveira verificou a possibilidade de desenvolver em seu projeto uma análise dentro do nível teórico as concepções de Corpo e Tempo em cada dissertação e tese, tendo como problema "Como os mestres e doutores em Educação Física do nordeste brasileiro (Estados de AL, PE, SE, BA) de 1982 a 2002, se posicionam e relacionam, em suas respectivas produções de pesquisa, sobre as concepções de corpo e tempo?” O projeto interligado se propõe recuperar as concepções de corpo e tempo abordadas nas áreas de formação profissional, escola, memória, cultura e corpo, políticas públicas, recreação/lazer, portadores de necessidades especiais, epistemologia, movimentos sociais, rendimento de alto nível, atividade física e saúde; e analisar com base no esquema paradigmático (instrumento de análise) as tendências teórico-metodológicas predominantes nessa produção.

Joelma de Albuquerque observou durante a graduação uma alienação curricular (Curso de Educação Física da UFAL - Universidade Federal de Alagoas) acerca das concepções de Ciência existentes e a indefinição de uma metodologia voltada para a produção científica, desarticulando assim, o tripé ensino-pesquisa-extensão e dissociando a teoria e prática. Estes fatores trazem como conseqüência à indefinição de um referencial teórico que venha clarear para os estudantes, idéias sobre os métodos científicos abordados por cada concepção de ciência, como por exemplo, as técnicas de coletas abordadas, autores fundamentais, relação sujeito-objeto etc. Para a obtenção de uma compreensão ampla da totalidade teórica que norteie as questões relacionadas com a área específica, elaborou o seguinte questionamento: "Quais as concepções de ciência apresentadas pelos mestres e doutores do nordeste brasileiro ( $A L, B A, P E, S E)$ de 1982 - 2002, através dos elementos do nível teórico do esquema paradigmático?"

${ }^{22}$ Ana Maria Pereira, assistente social, desenvolveu projetos de extensão junto ao Curso de "Vivências no Âmbito do Lazer Recreação em Instituições Públicas", e mais recentemente desenvolve o projeto "ESTIGMAS DA PROSTITUIÇÃO: portas abertas para violência contra a mulher profissional do sexo". Este projeto tem o objetivo geral de caracterizar como a subalternidade do gênero feminino e estigmas que permeiam a prostituição, interfere na relação prevenção-saúde da mulher profissional do sexo. Para desenvolvimento do trabalho, a pesquisadora considera a prostituição de mulheres um campo versátil para o desenvolvimento de trabalhos teóricos e uma questão social merecedora de especial intervenção. Nesse sentido, se propõe estudar e 


\section{RELATO DE EXPERIÊNCIA Área Temática: Filosofia da Educação}

Destacamos a importância da participação e o senso crítico dos estudantes na linha de pesquisa conforme podemos verificar na amostra de algumas conclusões dos relatórios individuais:

"As participações nos eventos citados foram de extrema importância para: a) A formação profissional como um todo; b) A opção pelo referencial teórico embasado pelo materialismo histórico dialético, o qual me sacia na sede de mudança desta realidade hipócrita e desigual; c) A compreensão da importância de uma linha de pesquisa no sentido de proporcionar a pesquisa coletiva e consequentemente obtermos força na realização dos nossos ideais de mudança; d) O conhecimento da epistemologia e sua importância na produção do conhecimento científico, único meio pelo qual podemos contestar a realidade de forma eficaz; e) A importância da pesquisa na formação profissional, a experiência proporcionada pela coordenadora da linha de pesquisa, na organização de eventos, condução de pesquisas, e do cotidiano VERDADEIRAMENTE ACADÊMICO e todos os itens acima citados, além da HONESTIDADE acadêmica, estando conosco todos os dias da semana como uma orientação incessante, além dos demais membros da linha de pesquisa LEPEL/UFAL/UFBA, UFS/UFPE."

\section{Outra participante assim se expressa:}

"Apesar de muito trabalhoso e desgastante, sei que este relatório será de grande importância, por possuírem todos os meus dados acadêmicos que foram possíveis colocar. Além da facilidade de encontrar tais dados quando se fizerem necessário."

E finalmente outro relatório explicita a importância na formação profissional da participação em atividades além das programadas no campo do ensino:

"Analisando as minhas participações em eventos científicos, projetos, cursos e disciplinas, posso concluir que foram de grande importância em minha vida acadêmica. Foi interessante perceber a minha evolução enquanto estudante, apresentando cada vez mais uma melhora em meus estudos. A Linha de Estudo e Pesquisa em Educação Física \& Esporte e Lazer (LEPEL) ajudou-me nessa caminhada de aprendizagem. É claro que o cansaço, as reuniões extras e a junção das disciplinas obrigatórias com os compromissos à parte, não foram tão fáceis de conciliar. Mas, o tempo mostrou-me o quanto isto me ajudou a crescer, e que se trata de uma questão de adaptação. Os conteúdos que aprendi, as experiências que vivi, as pessoas que conheci, os lugares que visitei, tudo isto foi de grande relevância para o meu desenvolvimento."

Os exemplos anteriores nos confirmar a importância da descoberta da problematização e do método científico como suporte para uma formação profissional que

diagnosticar em nível de mestrado: "Como os estigmas e símbolos evocados para representar a mulher profissional do sexo interferem na sua relação com a sociedade e na preservação da saúde e da sua integridade"? 


\section{RELATO DE EXPERIÊNCIA Área Temática: Filosofia da Educação}

redimensiona as diversas atividades realização na inter-relação dinâmica entre a universidade e a sociedade.

\section{CONCLUSÕES}

Destacamos a importância da problematização e dos métodos científicos no aprimoramento das ações pedagógicas e transformadoras do ensino e a extensão.

Em todos os projetos podemos identificar a prática da problematização como base das práticas pedagógicas e de extensão. A problematização induz para os campos da pesquisa porque obriga à formulação de indagações, questões e perguntas e a previsão de fontes, instrumentos e caminhos para elaborar as respostas aos problemas. Essa sistemática enriquece as práticas de ensino e de extensão, ultrapassando seus limites e motivando para novos processos de compreensão e de explicação da prática buscando relações com conteúdos disciplinares e confrontando sua validade perante os desafios da prática. Esses desafios assumidos pela maioria dos autores dos diversos projetos prosseguem em novos processos de aprofundamento crítico sobre as problemáticas levantadas nas referidas práticas e no confronto com os conteúdos disciplinares que se revelam pobres e insuficientes para a compreensão da complexidade da realidade na qual se inserem os projetos. A descoberta das limitações da teoria e a necessidade da compreensão da prática motiva e intensifica os processos de aprendizado da metodologia científica e consequentemente de produção do conhecimento.

Outro fator determinante das experiências acima registradas destaca a importância do grupo de estudos e pesquisas LEPEL que assume uma função de manutenção da dinâmica. Os projetos de ensino e de extensão não se esgotam na prática ou na sua execução. Nas avaliações são reconhecidos limites e dificuldades e novos desafios e práticas que poderiam terminar no simples registro. Da discussão coletiva desses relatórios sempre surgiram novas formas e estratégias para a continuação dos projetos ou para a ampliação e renovação das atividades como podemos constatar na reedição dos projetos "Brincando como antigamente" e no "Surto Cultural” já amplamente reconhecido pela universidade e com significativo apoio das pró-reitorias de pesquisa, extensão e estudantil. Nesse sentido, se os projetos não ganhassem a dinâmica da autocrítica e do aprimoramento metodológico do grupo de pesquisa certamente se esgotariam no primeiro relatório e não ultrapassariam o limite da atividade em 


\section{RELATO DE EXPERIÊNCIA Área Temática: Filosofia da Educação}

si mesma, nem acumulariam o conhecimento e experiência hoje registrada e socializada nesta comunicação.

O grupo de pesquisa oferece um significativo suporte teórico-metodológico e a orientação epistemológica, além da infra-estrutura institucional (pequena sala com computador ligada na rede Internet) e uma rede de intercâmbios em âmbito local (ômega) regional (Gama) nacional (Beta) e internacional (Alfa).

O aprimoramento metodológico e o suporte do grupo de pesquisa incentivaram a divulgação ampla dos resultados em eventos locais, regionais e nacionais. Por exemplo, no I Congresso de Extensão Universitária e no XIII Congresso de Ciências do Esporte.

Finalmente, as experiências acima analisadas justificam a importância do rigor científico no trato com os diferentes níveis e facetas do conhecimento humano e comprovam a possibilidade da articulação da extensão com o ensino e a pesquisa na formação profissional de jovens e adultos numa universidade pública do nordeste brasileiro.

\section{REFERÊNCIAS}

CHAVES, M. Recreação e Lazer no currículo de Educação Física. 2. ed. Maceió: EDUFAL, 2003.

; SÁNCHEZ GAMBOA, S. 2. ed. Prática de ensino: formação profissional e emancipação. Maceió: EDUFAL, 2003.

HABERNAS, J. Conhecimento e interesse. Rio de Janeiro: Zahar, 1982.

KOSIK, K. Dialética do concreto. Rio de Janeiro: Paz e Terra, 1976.

MARX, K.; ENGELS, F. A ideologia alemã: $1^{0}$ capítulo e separata das teses sobre Feuerbach. Lisboa: Avante, 1981.

MELO NETO, J. F. Extensão universitária: bases ontológicas. In: (Org.). Extensão universitária - diálogos populares. João Pessoa: Editora Universitária/UFPB, 2002.

RIBEIRO, D. A universidade necessária. 4. ed. Rio de Janeiro: Paz e Terra., 1982.

SÁNCHEZ GAMBOA, S. A pesquisa na construção da universidade: o compromisso com a aldeia num mundo globalizado. In: LOMBARDI, J. C. (Org.). Pesquisa em educação, 
história, filosofia e temas transversais. 2. ed. Campinas: Autores Associados; HISTEDBR, 2000, p. 77-93.

La investigación como estratégia de la innovación: Los abordajes prácticos. In: COMBESSIE, J. C.; SÁNCHEZ GAMBOA, S., et al. Investigación e innovación educativa. Santafé de Bogotá: Cooperativa Editorial Magistério, 1998, p. 77-106.

. Epistemologia da pesquisa em educação. Campinas: Práxis, 1996.

A dialética na pesquisa em educação: elementos de contexto. In: FAZENDA, I. Metodologia da pesquisa educacional. São Paulo: Cortez, 2002.

SAVIANI, D. Educação: do senso comum à consciência filosófica. Campinas, SP: Autores Associados, 2000.

TAFFAREL, C. As lições derivadas dos ACCs: a universidade outra - a universidade estratégica. Salvador: FACED/UFBA, 2001, mimeo. 
SILVIO SÁNCHEZ GAMBOA

Professor da FE/UNICAMP.

Líder do Grupo de Pesquisa PAIDÉIA.

E-mail: gamboa@unicamp.br

MÁRCIA CHAVES

Doutora em Educação, pesquisadora do Grupo LEPEL da UFBA e pesquisadora colaboradora convidada do Grupo PAIDÉIA da Faculdade de

Educação da UNICAMP

E-mail: chavesgamboa@gmail.com

Recebido em: 28/07/2008

Publicado em: 31/01/2009

\footnotetext{
Márcia CHAVES desenvolveu no período de 1990 a 1993, pesquisa apresentada como dissertação de Mestrado junto à Faculdade de Educação da Unicamp, a pesquisa: A disciplina Recreação e Lazer no currículo de formação de profissionais de Educação Física: o que dizem e fazem professores em universidades do nordeste do Brasil, hoje apresentados em $2^{\mathrm{a}}$ edição no livro Lazer e Recreação no currículo de Educação Física. Maceió: EDUFAL, 2003.
} 